\title{
Metagenomic analysis of saliva and biofilm microbiome of type 1 diabetics under continuous subcutaneous insulin infusion
}

\section{Carrilho $\mathrm{E}^{1}$, Coelho $\mathrm{A}^{2}$, Paula $\mathrm{A}^{1}$, Caramelo $\mathrm{F}^{1}$, Silva $\mathrm{M}^{2}$, Carrilho $\mathrm{F}^{3}$, Melo $\mathrm{M}^{3}$, Barros $\mathrm{L}^{3}$, Batista $\mathrm{C}^{3}$, Ferreira $\mathrm{M}^{1}$, Botelho $\mathrm{F}^{1}$}

\section{Introduction}

The microvascular complications of diabetes and consequent autonomic neuropathy may cause changes in the secretion and composition of saliva. Hyperglycaemic levels can also contribute to various oral pathological changes due to alterations of fungi and bacterial flora and of dental biofilm surface, leading to the onset of candidiasis, periodontitis and dental caries. ${ }^{1-6}$ So far there is a lack of studies concerning the bacterial load of saliva and biofilm in type 1 diabetics and none have investigated patients on continuous subcutaneous insulin infusion.

\section{Aim}

The aim of this study was to determine the total bacterial load of saliva and dental biofilm of diabetic patients on continuous subcutaneous insulin infusion and that of non-diabetics.

\section{Methods}

Twenty patients with type 1 diabetes on continuous subcutaneous insulin infusion were included in this study and 20 non-diabetic subjects were randomized as age-sex-matched controls. Unstimulated whole saliva and dental biofilm were collected from all patients under fasting conditions (at least $2 \mathrm{hrs}$ ). DNA was extracted from saliva and biofilm samples by adding Bacteria Lysis Buffer $\left(\right.$ Roche $^{\circledR}$ ) plus Proteinase K. The mixtures were incubated for $1 \mathrm{hr}$ at $65^{\circ} \mathrm{C}$, followed by an in-house extraction protocol based on DNA precipitation and isolation with cold ethanol. Total bacterial load was quantified by Real-time PCR (qPCR), using primers and targeting conserved bacterial 16S rDNA sequence in the LightCycler ${ }^{\circledR} 2.0$ instrument (Roche) by SYBR green detection. Data analysis was performed using IBM $^{\circledR}$ SPSS $^{\circledR}$ v.22.0 (IBM Corporation, Amrnonk, New York, USA) and the significance level was set at $5 \%$. Comparison of quantitative variables between the two groups was made using t-Student and Man-Whitney tests. Normality distribution of quantitative variables was assessed using Shapiro-Wilk test. For analysis of nominal variables the chi-square test was used. The Pearson and Spearman correlation tests were used to determine the strength of the relationships between variables.

\section{Results}

Diabetic patients had a statistically significant higher saliva and biofilm total bacterial load than non-diabetic subjects (Graphics 1 and 2). No statistically significant correlation was found between total bacterial load and glycated haemoglobin $A_{1 C}$ (Graphics 3 and 4).
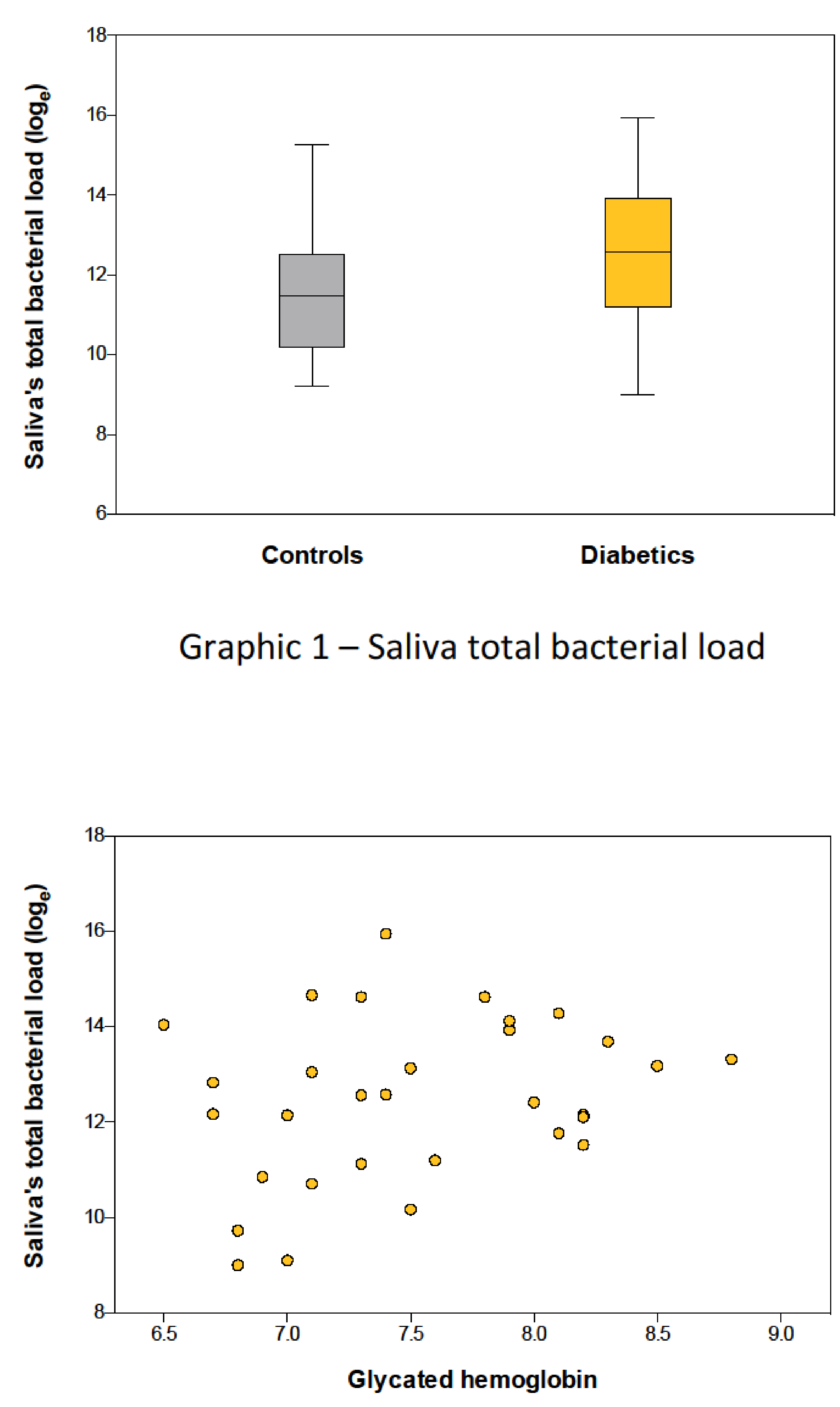

Graphic 3 - Correlation between serum $\mathrm{HbA}_{1 \mathrm{c}}$ levels and saliva total bacterial load
Graphic 1 - Saliva total bacterial load

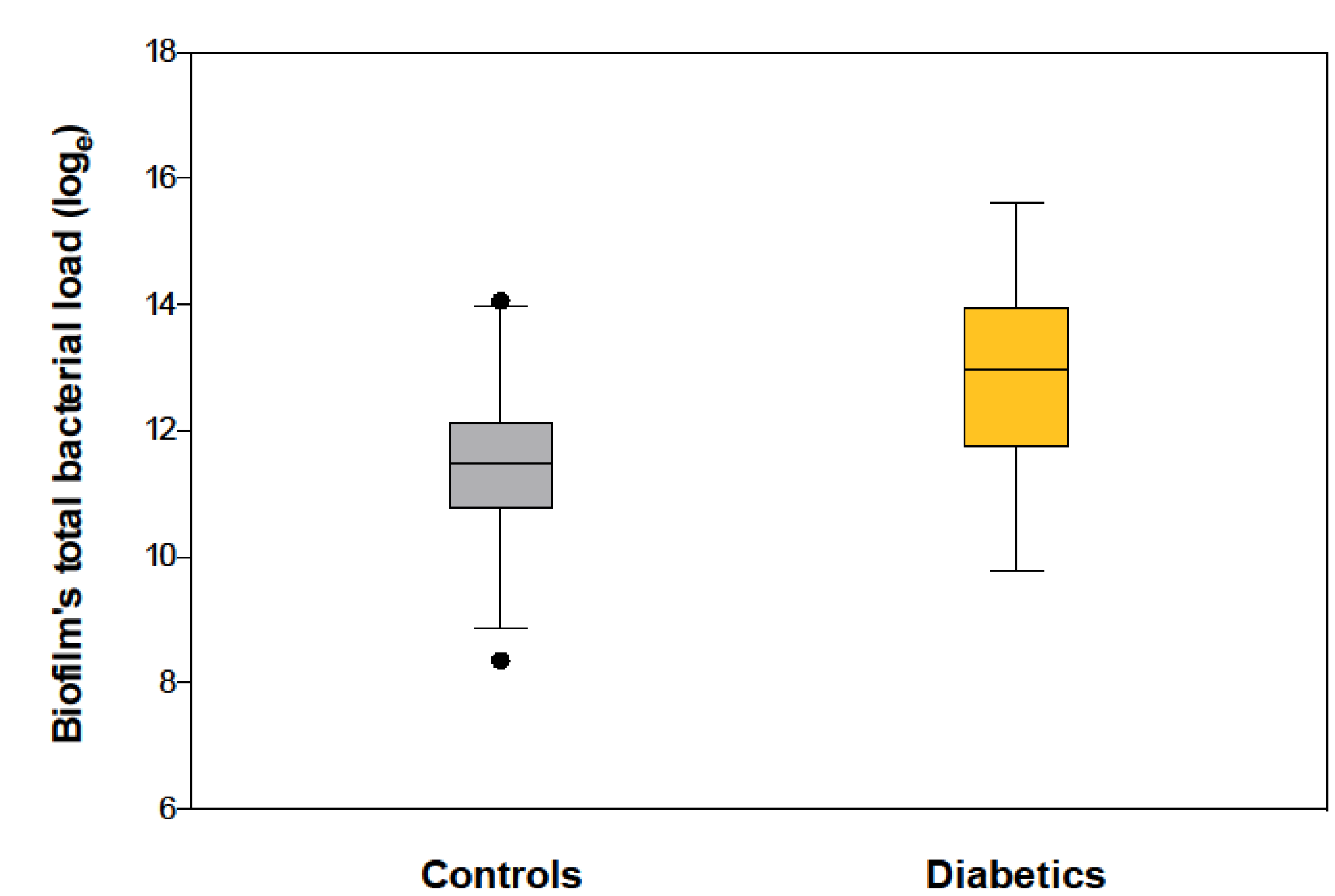

Graphic 2 - Biofilm total bacterial load

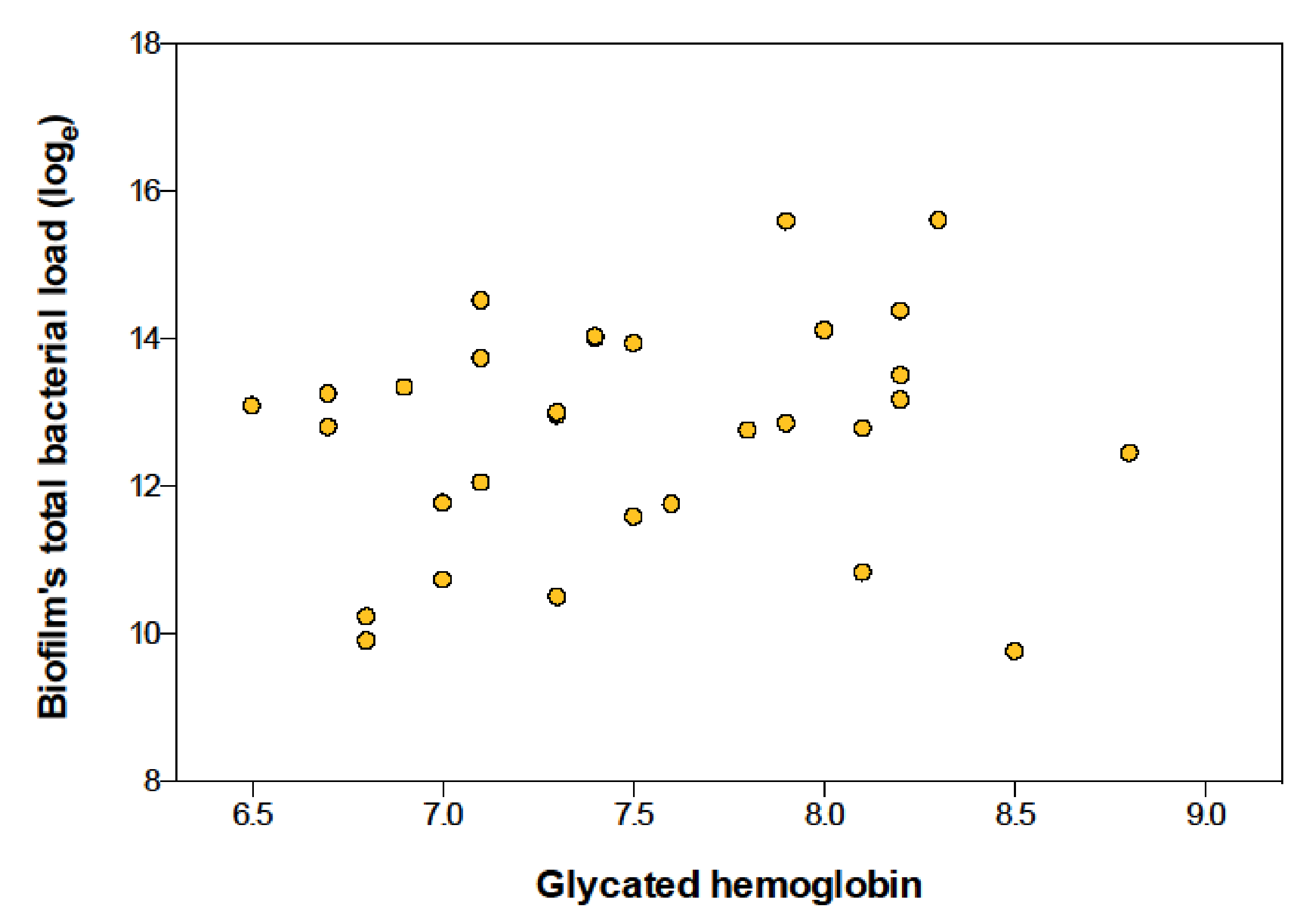

Graphic 4 - Correlation between serum $\mathrm{HbA}_{1 \mathrm{c}}$ levels and biofilm total bacterial load

\section{Conclusion}

This study suggests that type 1 diabetic patients have a higher saliva and biofilm total bacterial load than non-diabetic individuals, regardless of metabolic control. The higher bacterial load emphasizes the importance of effective dental control as well as the need to create new public health policies related to this population.

\section{References}

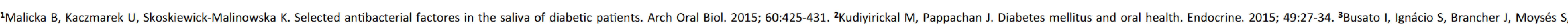

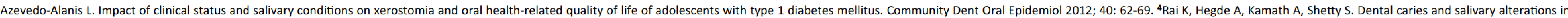

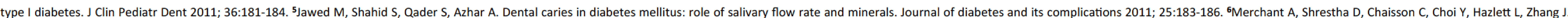
Association between serum antibodies to oral microorganisms and hyperglycemia in adults. J Dent Res 2014; 93:752-759. 